\title{
AIDS-Related Kaposi Sarcoma SO (Good Risk)
}

National Cancer Institute

\section{Source}

National Cancer Institute. AIDS-Related Kaposi Sarcoma SO (Good Risk). NCI Thesaurus.

Code C134982.

AIDS-related Kaposi sarcoma in which no systemic illness is present; there is no history of opportunistic infections or thrush and no B symptoms lasting more than 2 weeks. The Karnofsky performance status score is 70 or higher. (American Cancer Society) 